\title{
National Center on Minority Health and Health Disparities
}

National Cancer Institute

\section{Source}

National Cancer Institute. National Center on Minority Health and Health Disparities. NCI

Thesaurus. Code C82622.

A center within the National Institutes of Health with the mission to promote minority health and to lead, coordinate, support, and assess the NIH effort to reduce and ultimately eliminate health disparities. 